\title{
Organização das práticas de atenção primária em saúde no contexto dos processos de exclusão/inclusão social
}

\author{
Primary health care organization in the context \\ of social exclusion/inclusion processes
}

Nivaldo Carneiro Jr. 1

Cássio Silveira 1

\footnotetext{
1 Departamento de Medicina Social, Faculdade de Ciências Médicas, Santa Casa de São Paulo. Rua Cesário Motta Junior 61, 5o andar, São Paulo, SP 01221-020, Brasil. nicarneirojr@uol.com.br
}

Abstract This article reports on a primary health care and training center in São Paulo, Brazil, and the organization of its activities based on equity and positive discrimination. Operating in the city center of São Paulo, the policy aims to provide health services access to certain target groups (homel ess, sex workers, and slum-dwellers). It also rai ses di scussion on the various forms of social life found in downtown areas, mainly those of vulnerable groups lacking access to public goods and services. The experience demonstrates the feasi bility of implementing health policies based on universal access.

Key words Health Policy; Primary Health Care; Health Services

Resumo Este artigo apresenta a experiência de organização de um serviço de saú de em atenção primária, o Centro de Saúde-Escol a Barra Funda na ci dade de São Paulo, que privil egi ou o acesso dentro dos princípios da eqüidade e da discriminação positiva, criando condições de incorporar alguns segmentos que vivem na área central da cidade de São Paulo. São eles, os moradores de rua, as trabalhadoras do sexo e a população que habita em favelas. Promove, desse modo, uma reflexão acerca das variadas formas de vida social en contradas em áreas centrais de centros urbanos, em particular aquel as que vivem à margem dos processos de inclusão e sofrem graus acentuados de vulnerabilidade e marginalidade no acesso a bens e serviços. Também aponta para a possi bilidade de se implementar políticas de saú de que promovam intervenções eficazes junto a segmentos sociai s normal mente excluídos dos servi ços de saúde, efeti vando dessa forma o princípio da universalização.

Palavras-chave Políticas de Saúde; Cuidados Primários de Saúde; Serviços de Saúde 


\section{Intro dução}

A construção do Sistema Único de Saúde (SUS), a partir de 1988, garantiu em termos legais o acesso universal, igualitário e integral aos serviços e ações de saúde. Os caminhos percorridos até então demonstram o quão difícil tem sido criar o sentido da justiça social em uma sociedade tão injusta e desigual como a brasileira. Essa é uma tarefa complexa, principalmente em tempos de importantes transformações e rearticulações sociais, políticas e econômicas, em que o papel do Estado tem sido repensado.

Este artigo tem por finalidade expor experiências em atenção primária em saúde desenvolvidas no Centro de Saúde-Escola Barra Funda "Dr. Alexandre Vranjac" (CSEBF), da Faculdade de Ciências Médicas da Santa Casa de São Paulo (FCMSCSP), dentro do contexto de construção do SUS, colocando em prática os princípios constitucionais da universalidade e integralidade, articulados com a eqüidade no acesso ao serviço de saúde, e criando a possibilidade de responder às demandas heterogêneas dos diferentes grupos sociais assistidos na unidade, tais como: moradores, trabal hadores do mercado formal e informal, população de rua, profissionais do sexo, entre outros.

Parte-se da constatação da não existência de modelos programáticos prontos que viabilizem soluções imediatas a essa realidade, fato que gera a necessidade de ampliar o debate sobre as formulações conceituais, metodológicas e acerca das novas organizações tecnológicas dos serviços em saúde. Tal problema passa, necessariamente, pela discussão das transformações, nos planos conceitual e prático, das políticas de saúde no Brasil. Em particular, sobre as ações em atenção primária pelos serviços de saúde e a incorporação do debate sobre a noção de exclusão social.

\section{A atenção primária em saúde}

O SUS é resultado de um movimento social que há muito vem lutando por uma sociedade menos desigual, combatendo as iniqüidades no acesso às ações e aos serviços de saúde, na perspectiva da prevenção da doença e na promoção da saúde, esta entendida como direito do cidadão e dever do Estado para todos.

Desse modo, o SUS guarda nos seus princípios o ideário do resgate da cidadania, reconhecendo que, para alcançar seus objetivos, é necessário implementar políticas e correspondentes programas que contemplem as várias dimensões envolvidas no processo saúde-doença: habitação, transporte, alimentação, trabaIho, lazer, entre outros.

Sabe-se que a sociedade brasileira acumula anos de políticas públicas conservadoras, que a democracia ainda é um objetivo a ser atingido e que são necessárias lutas sociais cada vez mais amplas e articuladas com os canais de participação política para que os direitos sejam alcançados (Cohn, 2001).

A característica da construção da cidadania no Brasil tem um traço forte de concessão dada pelo Estado a grupos específicos, de acordo com os interesses das elites dominantes. " $\mathrm{Ci}$ dadania concedida" é a denominação dada por Sales (1994), a essa maneira de estabelecer direitos na nossa sociedade.

A conquista da legitimação do SUS, expresso na Constituição de 1988, ainda não representou uma real efetivação de programas que transformem os padrões de morbi-mortalidade pretendidos por meio das ações de saúde voltadas à população em geral, embora deva ser considerado um avanço na esfera jurídicolegal.

Perante essa realidade, como operar práticas de saúde orientadas para o exercício da cidadania? Como promover saúde para uma população bastante enferma e desprovida de recursos? Como lidar com a universalidade quando temos grupos populacionais sem acesso e com diferentes perfis sócio-demográficos e de saúde? Que instrumentos teóricos e práticos devem ser utilizados para fornecer respostas mais satisfatórias às demandas de saúde?

Essas são algumas perguntas formuladas e debatidas no cotidiano das práticas de saúde do CSEBF, inseridas por um esforço intelectual que orienta a procura de novas maneiras de organização tecnológica do trabalho em saúde, na perspectiva da implementação de políticas setorial e intersetorial equânimes e com fortes traços de discriminação positiva.

Neste sentido, promover a inclusão social significa tomar como recurso teórico-conceitual a categoria eqüidade. A eqüidade nas implementações de políticas significa não tratar de forma igual os desiguais, uma vez que a idéia de igualdade não se sustenta em si, mas é impregnada de valores morais e historicamente contextualizada (Rawls, 1992; Vita, 1992). Assim, a eqüidade promoverá ações aos grupos diferenciados em suas demandas e necessidades de diferentes maneiras, organizando programas que privilegiem alguns grupos populacionais identificados como mais despossuídos (Porto, 1995), caminho que tem demonstrado uma série de desafios. Entre eles podemos des- 
tacar: acordar no conjunto dos trabalhadores do serviço e nos usuários, em geral, ações que privilegiem alguns grupos sociais em detrimento de outros; manter o preceito constitucional da universalidade na assistência; manejar um instrumental teórico e metodológico para identificar quais os grupos populacionais a ser atingidos; e formular tecnologias adequadas para suas necessidades.

O nível de atenção primária em saúde tem se mostrado um campo fértil no desenvolvimento e incorporação de novas formas de organização da assistência à saúde. Desde a Conferência de Alma Ata em 1978, este nível de atenção foi colocado como uma estratégia de reorientação dos sistemas de saúde, na perspectiva da diretriz "saúde para todos no ano 2000" (Paim, 1999).

Segundo Elias (2001), a divisão entre os níveis de atenção primário, secundário e terciário é uma forma abstrata de conceber o sistema de saúde, diferenciando-os de acordo com o grau de incorporação de tecnologia material e de especialização de seus recursos humanos. A atenção primária constitui a instância de menor grau de incorporação destes elementos.

Autores como Schraiber \& Mendes-Gonçalves (1996) e Merhy (1997), apontam para a especificidade tecnológica do trabalho em saúde na atenção primária, ou básica, como um importante processo de produzir saúde, pois é nesse espaço onde há possibilidade mais efetiva da promoção da autonomia do cuidado em saúde, visto que essa modalidade de serviço está menos aprisionada ao trabalho médico restrito.

No Brasil, algumas experiências realizadas até então, cujas ações visam a dar cobertura à saúde da população por meio de programas ou formas variadas de assistência dentro dos princípios doutrinários e organizacionais do SUS, indicam os caminhos tomados na construção do mesmo. Na atenção primária em saúde, por exemplo, foram implementados em boa parte do território nacional o programa de agentes comunitários de saúde e o programa de saúde da família, na tentativa de estender ações básicas em saúde aos segmentos da população até então sem acesso aos serviços de saúde. Os dois programas desdobraram-se, primeiramente, em projetos regionais e, posteriormente, municipais, assumindo configurações variadas dentro da orientação de privilegiar as necessidades em saúde de cada localidade ou região do país, segundo os princípios constitucionais. Ocorre que, mesmo com a expansão de ações básicas em saúde no país, ainda que muitas vezes instituídas sem o acompanhamento de processos avaliativos, outras experiências em atenção pri- mária, cuja finalidade é incluir segmentos não assistidos pelas políticas em saúde, têm sido experimentadas no território nacional.

Portanto, é no contexto urbano de uma grande metrópole, como é o caso da cidade de São Paulo, que se insere o CSEBF, desenvolvendo práticas de atenção primária em saúde em uma realidade urbana heterogênea e plena de relações sociais complexas que é a região central do Município de São Paulo. Alguns segmentos sociais que ocupam espaços na área central têm recebido desse serviço ações específicas, cuja finalidade é poder ofertar tecnologias que efetivamente saibam reconhecer problemas em saúde, assim como dar respostas a estes. A particularidade desses segmentos, a exemplo dos moradores de rua, requer um conjunto de ações especiais, que envolvem desde a capacitação dos agentes de saúde até a organização do processo de trabalho.

\section{O contexto urbano - território de inclusão e exclusão social}

A definição de cidade está nas origens dos fenômenos de urbanização que pressupõem a construção de áreas centrais e periféricas, nas quais as pessoas vivem, trabalham, moram, adoecem e morrem. Desde o seu surgimento, as cidades já se constituíam como espaços nos quais conviviam diferentes classes sociais e atividades econômicas.

A preocupação com a cidadania, com a democratização e, principalmente, com o aumento da violência e da pobreza nas cidades vem reforçando o interesse pela pesquisa sobre a questão urbana e a problemática dos segmentos que convivem no mesmo espaço, seja pela moradia ou pelo trabalho (Kowarick, 1995). Inclui-se, neste caso, a busca de conhecimentos sobre as estratégias de sobrevivência dos vários grupos que vivenciam processos amplos de exclusão econômica, social, política e cultural.

No caso particular de São Paulo, Santos (1994) caracteriza a região metropolitana como um espaço que apresenta uma acentuada fragmentação social expressa em uma composição populacional diferenciada e que abriga a convivência de diversas formas de produção, distribuição e consumo. Por isso mesmo, é uma área onde se revelam inúmeros conflitos, em uma coexistência cujos sentidos confundemse com os interesses pela ocupação de espaços públicos, com a delimitação dos espaços privados, com as trocas comerciais, com a prestação de uma infinidade de serviços. No mesmo sentido, só que incorporando o debate sobre a cul- 
tura, Canevacci (1993) chama a atenção para o caráter fragmentário, de justaposi ção conflituosa e para o sincretismo cultural que as grandes metrópoles apresentaram na última década - as "cidades polifônicas".

O centro histórico da cidade de São Paulo demonstra características evidentes de popularização, empobrecimento e diversificação quando comparado ao centro tradicional do início do século. Em meados das décadas de 50 e 60, começou a exibir sinais de deterioração, com a presença do comércio informal, da violência e da pobreza. Essa tendência acentuouse nas décadas de 70 e 80 , chegando aos anos 90 com uma situação de extrema heterogeneidade entre os vários grupos sociais que ali convivem no dia-a-dia e que demandam serviços aos recursos existentes no local e nas áreas mais próximas (Frugoli Jr., 1995).

A heterogeneidade e deterioração determinam, por sua vez, uma segregação espacial entre pobres e ricos, centro e periferia, e uma divisão de "pedaço" entre os diversos grupos, que autores como Maffesoli (1987), denominam de "tribos", estabelecendo redes de relações sociais e tornando possível a própria cidade. Nesses "pedaços", as necessidades individuais conjugam-se às expectativas e às possibilidades de inserção social, levando à construção de “identidades" em meio às privações e desigualdades de oportunidades (Magnani, 1984). As desigualdades sócio-econômicas, a incongruência entre os anseios e as condições concretas para satisfazê-los, além de influenciar as diferentes experiências de adoecer e morrer entre grupos populacionais, são ainda responsáveis pelas condições de estresse e problemas de saúde mental (Nakamura, 1996).

Os estudos da área de saúde, mesmo com a preocupação de definir um território para atuação, não têm incorporado essa problemática. No conjunto da população local, chega-se a definir grupos prioritários para a atenção, considerando sua maior vulnerabilidade às patologias, mas não se chega a constituir modelos de atenção que articulem respostas diferentes às demandas de grupos sociais heterogêneos, que dividem o mesmo espaço territorial, econômico e cultural.

Apontamentos sobre as condições de vida na área central da Cidade de São Paulo

De acordo com a Lei Municipal no 11.220 (São Paulo, 1992), de 20 de maio de 1992, o Município de São Paulo é dividido em 96 distritos ad- ministrativos. Destes, dez constituem a região central: Sé, República, Santa Cecília, Bom Retiro, Pari, Brás, Cambuci, Liberdade, Consolação e Bela Vista. Segundo o Censo de 2000, há 413.896 habitantes nessa região, sendo o distrito de Santa Cecília o mais populoso (71.179 habitantes) e o do Pari o menos habitado, com 14.824 habitantes (IBGE, 2000). Esses dez distritos ocupam uma área geográfica de $32,6 \mathrm{~km}^{2}$, 2,2\% da área do município (1.509km²).

A zona central aglutina grande parte dos serviços de diferentes ramos de atividades, atraindo volumosos segmentos populacionais que a utilizam como local de consumo, moradia e/ ou trabal ho. O traçado da malha viária da cidade favorece esse fluxo, concentrando na região os principais troncos rodoviário, ferroviário e metroviário.

Segundo o ranking do Mapa da Exclusão/ Inclusão Social da Cidade de São Paulo 2000 (Sposati, 2000), os dez distritos administrativos da área central estão em situação mediana em relação aos demais. Todavia, há diferenças entre eles, podendo ser, assim classificados: (a) melhores condições - Bela Vista, Cambuci e Consolação; (b) médias condições - Bom Retiro, Liberdade, Pari e Santa Cecília; (c) piores condições - Brás, República e Sé.

Nesse diagnóstico, merecem ser feitos alguns destaques: a presença marcante de cortiços como importante característica habitacional da região e os núcleos recentes de favelas e de população de rua. Esses são alguns aspectos que marcam definitivamente situações de exclusão social, que serão abordadas posteriormente neste texto.

Estudo realizado pela Secretaria Municipal do Desenvolvimento, Trabalho e Solidariedade, da Prefeitura do Município de São Paulo, para o ano de 2000 (São Paulo, 2002), classificou esses distritos de acordo com o Índice de Desenvolvimento Humano (IDH) em três grupos: médio (Consolação, Bela Vista, Liberdade e Santa Cecília), baixo (Bom Retiro, Brás, República e Cambuci) e muito baixo (Sé e Pari).

\section{O CSEBF: características do serviço e de sua área de abrangência}

O CSEBF tem por objetivos: prestar assistência à saúde, formar e capacitar recursos humanos em saúde e desenvolver investigações voltadas para o campo da saúde coletiva, especialmente no que se refere à formulação de novas tecnologias em atenção primária em saúde (FAVC/ I rmandade da Santa Casa de Misericórdia de São Paulo/SES-SP, 2001). 
A área de abrangência do CSEBF estendese por um território pertencente aos distritos administrativos da Barra Funda, do Bom Retiro e de Santa Cecília, cobrindo uma população de aproximadamente 32 mil habitantes (IBGE, 2000).

A separação em distritos administrativos obedece a uma divisão formal, pois as áreas citadas são contíguas, tendo dinâmicas sócio-urbanas semelhantes. Neste sentido, a região central da cidade de São Paulo desponta como espaço de destaque na análise e diagnóstico para o planejamento e as ações de saúde do serviço, procurando, desse modo, entender as diferentes demandas e as várias possibilidades de identificação das necessi dades em saúde a ser trabalhadas.

Tradicionalmente, o CSEBF tem assistido os segmentos da população que habita a região, assim como trabalhadores do comércio, serviços e indústria existentes na área. O aparecimento de novos grupos sociais, tais como moradores de rua, imigrantes bolivianos, ambulantes e profissionais do sexo, tem suscitado a necessidade de formular novas abordagens (individuais e coletivas) em saúde.

Essas novas abordagens conduzem, necessariamente, a mudanças internas na organização, afirmação evidenciada, primeiramente, pela criação de um conjunto de reflexões com os agentes de saúde, especialmente sobre as mudanças na dinâmica social, isto é, sobre as novas formas de interação e sociabilidade que vão se desenvolvendo na área central da cidade e suas conseqüências para a saúde da população (Silveira, 1999).

Em 1968, quando de sua instalação, foi realizado um censo demográfico da área, traçando um diagnóstico das condições de vida e saúde da população residente, o qual objetivava servir de instrumento para a concepção e organização do modelo assistencial a ser operacionalizado.

O modelo assistencial instalado foi a programação em saúde (Nemes, 1990). Esse modelo serviu, em muitos casos, como campo de experimentação para que a Secretaria de Estado da Saúde de São Paulo (SES-SP) pudesse implementar programas em sua rede de serviços.

No início, definiu-se como população-alvo das ações em saúde os moradores da região. Foram cadastrados no serviço em prontuários do tipo "ficha família", tendo acesso às modalidades de assistência à saúde da unidade, por meio de consultas agendadas e fora do agendamento, no pronto-atendimento.

A partir da segunda metade da década de 80 , uma nova realidade apresentava-se à região e, conseqüentemente, ao CSEBF: empresas do setor terciário da economia passaram a ocupar os espaços outrora habitados por antigos moradores. Essa transformação foi impulsionada, principalmente, pelo processo de reorientação urbana ocorrido na Barra Funda, com a instalação do Terminal Intermodal (sistemas metroviário, ferroviário e rodoviário) e do Memorial da América Latina, caracterizando o bairro como um local de serviços e, desse modo, assemelhando-se à dinâmica da urbanização da área central de São Paulo.

Naquele momento, percebeu-se a necessidade da estruturação de um programa de saúde do trabalhador em nível de atenção primária. Realizou-se um censo dos estabelecimentos comerciais da região, para a obtenção de dados quanto ao ramo de atividade, riscos potenciais, números de empregados, entre outros. Foram elaborados prontuários por empresa - "ficha empresa", contendo a relação dos empregados.

Portanto, moradores e trabalhadores do mercado formal são os dois grandes grupos populacionais que o CSEBF vem atendendo por meio da assistência médica individual ou das ações de saúde pública, dentro do modelo assistencial da programação em saúde.

Usuários que não se enquadram em um desses dois grupos são assistidos no prontoatendimento (PA). Suas queixas são acolhidas e procura-se reorientá-los para serviços de saúde localizados próximos às suas residências.

Nos últimos anos, tem aumentado no PA a demanda oriunda de população não matriculada - moradores de rua, migrantes em situação irregular no país, profissionais do sexo, entre outros. Para o serviço, estes são os novos sujeitos sociais que, ao aparecerem em cena, trazem singularidades muito distintas, não se adequando às rotinas programáticas estabelecidas para os usuários tradicionais.

A heterogeneidade de necessidades de saúde desses grupos tem exigido respostas diferenciadas por parte de um serviço que, tradicionalmente, vinha trabalhando com uma demanda que se enquadrava na rotina das consultas programáticas, nas orientações preventivas e no seu "fichamento" por meio das matrículas, mediante comprovante de residência ou de trabalho (Marsiglia \& Carneiro Jr., 1997).

Como trabalhar com essa diversidade? Que tecnologias são necessárias para abordar e intervir na perspectiva da saúde coletiva para tais grupos populacionais? Que perfil de recursos humanos é exigido para trabalhar com essa realidade específica?

Diante da realidade sócio-demográfica da área de inserção do serviço, tem-se elaborado 
modos de organização do trabalho em saúde, cuja grande preocupação é poder compreender e dar respostas aos problemas de saúde dos vários grupos populacionais inseridos desigualmente na estrutura social.

Neste sentido, a problematização da noção de exclusão social tem-se colocado como central nesse processo, buscando seu melhor entendimento para que se possa formular novos modos de organização das práticas que resultem em eficácia social.

\section{"Exclusão/inclusão social" e modos de organização do trabalho em saúde}

Apesar das críticas de diversos autores sobre o uso do termo exclusão social para designar situações desfavoráveis nas condições sociais e econômicas de indivíduos e grupos sociais, a discussão em torno do termo exclusão social assumiu contornos de um debate profícuo sobre a realidade social no capitalismo contemporâneo.

A principal crítica a essa forma de nominar situações de inserções desfavoráveis na estrutura social, as quais geram modos diferenciados de acesso aos bens sociais, é que tal denominação cristaliza uma situação, tornando-a estática no tempo e no espaço. Perde-se, portanto, a noção de dinâmica, característica constitutiva da noção de exclusão. Assim, "falar em termos de exclusão é rotular com uma qualificação puramente negativa que designa a falta, sem dizer no que ela consi ste nem de onde provém" (Castel, 1997a:19). Ou seja, com essas limitações perde-se a oportunidade de ampliar o potencial explicativo da noção, já que a mesma encerra um caráter generalizador ao entendimento de processos que conduzem alguns segmentos sociais menos favorecidos a viver em condições precárias, seja em decorrência da diminuição dos níveis de renda, seja pela perda de vínculos societários que mantêm o elo de ligação entre familiares e outras formas associativas da vida social.

Essa preocupação teórico-metodológica também está presente no pensamento de autores brasileiros, como Martins (1997), que coloca a discussão no plano da inclusão precária, instável e marginal, obedecendo à própria lógica do mundo capitalista.

Por sua vez, Nascimento (1994) chama a atenção para a questão da exclusão social pelo significado que o termo pode assumir de rupturas na coesão dos vínculos sociais, ou seja, das fraturas criadas nos laços de solidariedade, levando a processos de não reconhecimento do outro como portador de direitos. Nesta perspectiva, classifica a exclusão em três formas de expressão: (a) discriminação de qualquer ordem - racial, sexual, religiosa, entre outras; (b) exclusão de direitos - os desempregados, os trabalhadores do mercado informal etc. e (c) nova exclusão - população de rua, grupos populacionais sem assistência nenhuma, entre outros.

O mais grave nessa caracterização é que, no caso brasileiro, “(...) o nosso processo de desenvolvimento tende a produzir um novo tipo de exclusão social, cujo resultado será a transformação do incluído incômodo, o pobre que alcançou o estatuto de el eitor, no excluído perigoso, desnecessário do ponto de vista da economia (...) e ameaçador, do ponto de vista social, pois transgressor dasleis" (Nascimento, 1994:44).

Tal debate lança a possibilidade de compreensão da situação de determinados grupos populacionais que habitam a área central da cidade de São Paulo, colocando-os, dentro de uma perspectiva teórica específica, na situação de exclusão social, de desfiliação, ou evidenciando precárias formas de inserção institucional e social. Assim, pode-se observar que a população adulta de rua que ocupa os logradouros do centro da cidade - as profissionais do sexo que ocupam espaços públicos, além dos moradores de favelas construídas sob os viadutos ou nas margens das ramificações hídricas que cruzam a cidade - constitui expressão de uma situação que promove novas formas de sociabilidade.

No contexto das várias atividades de prestação de serviços organizadas pelo CSEBF, observou-se que o modelo estruturado não possibilitava a inserção dos segmentos acima citados. Neste sentido, um conjunto de atividades que possibilitassem a reflexão sobre as especificidades de cada segmento social, e o encaminhamento das demandas e necessidades colocadas ao serviço passou a ser desenvolvido na unidade.

Inicialmente, formou-se um grupo de estudos coordenado pela direção da unidade. Os debates circunscreviam as potencialidades e limites da aplicação da noção de exclusão social, em suas várias acepções, e, o que era fundamental, seus desdobramentos no conjunto de reflexões promovidas pelo campo de estudos em saúde. Com isso, criou-se a oportunidade de refletir sobre as práticas internas, o desenvolvimento de novas formas de atendimento que incorporassem dinâmicas sociais peculiares a cada segmento e, ainda, passaram a ser construídos e executados alguns projetos de pesquisa que ampliassem os conhecimentos 
fomentados na unidade (Andrade \& Silva, 1999; Carneiro Jr. et al., 1998; Maezuka et al., 1999).

Um dos grupos que mais se destacam no debate sobre a exclusão social é a população de rua. Nascimento (1994), chama-os de novos excluídos, aqueles que "não têm direito de ter direitos". Fenômeno marcadamente característico de regiões centrais de metrópoles, tem-se apresentado como um fenômeno social qualitativamente diferente nessas últimas décadas, passando de grupos constituídos de migrantes nordestinos, para serem cada vez mais grupos de indivíduos originários da região sudeste, principalmente do Estado de São Paulo, com níveis mais elevados de escolarização e histórico de vida que inclui atividades de trabalho. Ainda que a questão econômica seja a principal explicação para o fato de estarem vivendo na rua, havendo hoje famílias morando em logradouros públicos, várias causas de ordem familiar e de doença também contribuem para a trajetória de ir para a rua. Define-se como população em situação de rua aqueles que utilizam a rua como lugar de trabalho e moradia (Rosa, 1995; Vieira et al., 1992).

Em 1996, pesquisa realizada constatou algumas situações impressionantes em relação às formas de contato dessa população com os serviços de saúde, as quais revelaram iniqüidades bastante claras no acesso à assistência, tais como: exigência de comprovante de residência para matrícula em serviços de saúde, maus tratos no atendimento em decorrência de aspectos relacionados à ausência de cuidados de higiene pessoal e ao alcoolismo, dificuldade para internações em hospitais de retaguarda por não possuírem famílias que se responsabilizassem por eles, entre outras (Carneiro Jr. et al., 1998).

Muito próximo a esse grupo, mas com suas particularidades, estão as mulheres que se prostituem na região da Luz. Sujeitas à violência por parte de clientes, policiais e comerciantes, entre outros, submetem-se, muitas vezes, a relações sexuais em troca de uma noite em hotel da redondeza, para não ficarem na rua. Desse modo, não se reconhecem como pertencentes ao mesmo processo de inserção precária e de discriminação do grupo população de rua, demonstrando também uma dinâmica diferenciada em relação às formas do adoecer (Andrade \& Silva, 1999)

O que se percebe nas características desses dois grupos sociais são constituições de modos particulares de vida que, de alguma forma, se articulam com o todo social. Podemos citar, entre outras, duas situações que ilustram certas particularidades desses grupos: a maneira de lidar com situações de agravos à saúde e a utilização dos serviços de saúde.

Com relação aos cuidados com os agravos à saúde, percebe-se a valorização, ou não, de certas enfermidades ou riscos de adoecer, desde que não impeçam a locomoção, no caso da população de rua. No caso das profissionais do sexo, desde que os agravos não atrapalhem suas atividades de trabalho, quando apresentam doenças sexualmente transmissíveis sentidas.

$\mathrm{Na}$ segunda situação, em relação à utilização dos serviços de saúde, esses segmentos seguem as propostas terapêuticas de maneira assistemática e esporádica. Como exemplo desta situação, há o não comparecimento aos agendamentos efetuados na unidade de saúde e, também, o uso irregular da medicação prescrita. Ambos os grupos apresentaram estas tendências.

Um outro grupo social que se distingue dos dois anteriores, mas com alta vulnerabilidade social, e que nos tem trazido questões de interface com o processo de exclusão social, são os moradores da Favela dos Gatos - localizada às margens do rio Tamanduateí, no distrito administrativo do Bom Retiro. Possui cerca de trezentas unidades habitacionais, sendo uma boa parte do tipo palafita, residindo lá por volta de mil habitantes. As seguintes características nos chamam a atenção: é um agrupamento habitacional que reúne grupos heterogêneos; moram em uma área de invasão, com precárias condições sanitárias e sem infra-estrutura de urbanização, constituindo uma área de risco; apresentam processos de rupturas sociais muito visíveis, com sérias ocorrências de casos de violência urbana, motivadas, principalmente, pelo tráfico de drogas. Por meio da assistência à saúde, principalmente às mulheres gestantes e às crianças, têm sido estabelecidos contatos com esses moradores, com o intuito de entender sua dinâmica social e construir pontes para uma possível atuação, no sentido de buscar, junto com a comunidade, outras formas de inserção desses indivíduos (Maezuka et al., 1999).

Podemos considerar os moradores da Favela dos Gatos situados no que se denomina de "zona de vulnerabilidade", caracterizada pela existência de trabalhos precários e inserção social frágil. Essa zona “(...) ocupa uma posição estratégica. É um espaço social de instabilidade, de turbulência (...). É a vulnerabilidade que alimenta a grande marginalidade ou a desfiliação" (Castel, 1997b:25-26).

Para esses três grupos sociais, a organização da assistência à saúde pelo CSEBF tem sido realizada de maneira que se possa responder e/ ou encaminhar as demandas de saúde 
apresentadas por eles, ou identificadas no momento da interação entre nossa equipe de saúde e indivíduos portadores de alguma queixa. Ou seja, procura-se resolver, o máximo possível, o problema, seja nas esferas do psíquico e do biológico - aplicação de medicamentos, coleta de exames, atendimentos individuais, entre outros - , seja na esfera da assistência social - encaminhamentos para equipamentos sociais, orientação previdenciária etc. Também foram organizadas inserções nas agendas dos profissionais para que se privilegiassem as oportunidades de contato com o serviço, possibilitando, dessa maneira, a criação de vagas, o que não ocorre, em geral, com os outros seguimentos populacionais, que têm de agendar consultas, caso não seja de urgência. Assim, o acolhimento desses grupos populacionais configura uma forma diferenciada e prioritária, quando comparada àquela realizada com a maioria dos usuários da unidade, os quais entram na rotina do agendamento na forma tradicional do trabalho comumente organizada no serviço de saúde pública.

\section{Considerações finais}

Ao tratar das questões de saúde relativas a esses grupos sociais "excluídos", faz-se necessário buscar as articulações possíveis, no que tange à noção de valor da vida e da saúde nesse contexto singular. Algo que permita que a ação de saúde não seja apenas pontual, no sentido de avaliar um sofrimento agudo, mas, principalmente, uma ação de saúde que sirva de instrumento de resgate do valor da vida e da saúde, da cidadania, da dignidade humana e do centro afetivo-intelectual do indivíduo. Centro esse que facilmente se deteriora, dentro dos processos de luta pela sobrevivência, que acabam desumanizando as relações sociais. Com isso, o centro afetivo-intelectual re- vela-se como uma metáfora, ao mesmo tempo individual e coletiva, pois o próprio centro da cidade pode ser visto dessa maneira, sofrendo processos equivalentes, em um jogo especular de infinitas ressonâncias.

Para Gerschman (1995:31), “a incorporação da eqüidade na concepção da democracia e a maneira de implementá-la (...) [parecem] ser uma das questões substanti vas que hoje se colocam para o Brasil e outros países que atravessaram regimes autoritários e se encontram com enorme parcela de sua população no limite da pobreza absoluta". Portanto, esse tem sido um grande desafio e uma grande dificuldade para as políticas públicas, especialmente as de saúde, com seu ideário universalizante.

Neste sentido, a experiência do CSEBF relatada anteriormente, ao identificar grupos sociais em situação de vulnerabilidade e organizar o serviço na perspectiva da eqüidade do acesso por meio da discriminação positiva, tem-se mostrado satisfatória ao incorporar em sua organização tecnológica do trabalho, segmentos sociais em situação de exclusão social. Mesmo reconhecendo os limites e as armadiIhas dessas políticas de discriminação positiva, como já assinalado por Castel (1997b), que alerta para a el evação do grau de cristalização de preconceitos, estigmas ou mesmo o risco de não ser desenvolvida a autonomia de indivíduos e grupos, tornando-os dependentes de políticas compensatórias, acredita-se ser esta uma política necessária de inclusão, que deve ser monitorada para que sejam reconhecidos seus fatores limitantes.

Este é o cenário de atuação e de problematização, identificando os limites e as possibilidades de lidar com as políticas públicas em uma sociedade de profundas iniqüidades sociais. Todavia, acreditamos ser este o nosso papel: apontar, refletir e exigir que o Estado, por meio de seus recursos públicos, cumpra suas funções de promover a justiça social.

\section{Referências}

ANDRADE, M. C. \& SILVA, J. L., 1999. DST em trabaIhadoras do sexo: Vulnerabilidade e exclusão. In: VI Congresso Paulista de Saúde Pública, Livro de Resumos, p. 18, Águas de Lindóia: Associação Paulista de Saúde Pública.

CANEVACCI, M., 1993. A Cidade Polifônica: Ensaio Sobre a Antropologia da Comunicação Urbana. São Paulo: Editora Nobel.

CARNEIRO Jr., N; NOGUEIRA, E. A.; LANFERINI, G. M.; MARTINELLI, M. \& AMED ALI, D., 1998. 
Serviços de saúde e população de rua: Contribuição para um debate. Saúde e Soci edade, 7:4762.

CASTEL, R., 1997a. As armadilhas da exclusão. In: Desigualdade e a Questão Social (L. Bógus, M. C. Yazber \& M. Belfiore-Wanderley, org.), pp. 15-48, São Paulo: Educ.

CASTEL, R., 1997b. A dinâmica dos processos de marginalização: Da vulnerabilidade à "desfiliação". Cadernos CRH, 26/27:19-40.

COHN, A., 2001. A saúde na previdência social e na seguridade social: Antigos estigmas e novos desafios. In: Saúde no Brasil: Políticas e Organização de Serviços (A. Cohn \& P. E. Elias, org.), pp. 13-57, São Paulo: Editora Cortez/Centro de Estudos e Cultura Contemporânea.

ELIAS, P. E. M., 2001. Estrutura e organização da atenção à saúde no Brasil. In: Saúde no Brasil: Políticas e Organização de Serviços (A. Cohn \& P. E. Elias, org.), pp. 59-119, São Paulo: Editora Cortez/ Centro de Estudos e Cultura Contemporânea.

FRUGOLI J r., H., 1995. São Paulo: Espaços Públicose Interação Social. São Paulo: Editora M arco Zero/ Serviço Social do Comércio.

FAVC (Fundação Arnaldo Vieira de Carvalho)/IRMANDADE DA SANTA CASA DE MISERICÓRDIA DE SÃO PAULO/SES-SP (Secretaria de Estado da Saúde de São Paulo), 2001. Centro de Saúde-Escola Barra Funda: Projeto Específico para o Ano 2002. São Paulo: FAVC/Irmandade da Santa Casa de Misericórdia de São Paulo/SES-SP. (mimeo.)

GERSCHMAN, S., 1995. A Democracia Inconclusa: Um Estudo da Reforma Sanitária Brasileira. Rio de Janeiro: Editora Fiocruz.

IBGE (Fundação Instituto Brasileiro de Geografia e Estatística), 2000. Censo Demográfico 2000. Rio de Janeiro: IBGE.

KOWARICK, L., 1995. Investigação urbana e sociedade. In: Pluralismo, Espaço e Pesquisa (E. Reis, M. H. T. Almeida \& P. FRY, org.), pp. 45-57, São Paulo: Associação Nacional de Pós-Graduação e Pesquisa em Ciências Sociais/Editora Hucitec.

MAEZUKA, A. T.; BELLESO, M.; RIBEIRO, M. A. \& NAVES, T. M., 1999. Estudo do Projeto "Favela dos Gatos". São Paulo: Centro de Saúde-Escola Barra Funda/Faculdade de Ciências Médicas da Santa Casa de Misericórdia de São Paulo.

MAFFESOLI, M., 1987. O Tempo das Tribos: O Declínio do Individualismo nas Soci edades de Massa. Rio de Janeiro: Editora Forense-Universitária.

MAGNANI, J. G. R., 1984. Festa no Pedaço: Cultura e Lazer na Cidade. São Paulo: Editora Brasiliense.

MARSIGLIA, R. \& CARNEIRO J r., N., 1997. Condições de vida e saúde na região central de São Paulo. In: $\checkmark$ Congresso Brasileiro de Saúde Coletiva \& Congresso Paulista de Saúde Pública, Livro de Resumos, p. 21, Águas de Lindóia: ABRASCO/Associação Paulista de Saúde Pública.

MARTINS, J. S., 1997. Exclusão Social e a Nova Desigualdade. São Paulo: Editora Paulus.

MERHY, E. E., 1997. A rede básica como uma construção da saúde pública e seus dilemas. In: Agir em Saúde: Um Desafio para o Público (E. E. Merhy \& R. Onocko, org.), pp. 197-228, São Paulo: Editora Hucitec/Buenos Aires: Lugar Editorial.

NAKAMURA, E., 1996. Algumas considerações antro- pológicas sobre o processo de urbanização e suas conseqüências sobre a saúde mental das crianças. Infanto, Revista de Neuropsiquiatria da Infância e Adolescência, 4:52-56.

NASCIMENTO, E. P., 1994. Hipóteses sobre a nova exclusão social: Dos excluídos necessários aos excluídos desnecessários. Cadernos CRH, 21:29-47.

NEMES, M. I. B., 1990. Ação programática em saúde: recuperação histórica de uma política de programação. In: Programação em Saúde Hoje (L. B. Schraiber, org.), pp. 65-116, São Paulo: Editora Hucitec.

PAIM, J. S., 1999. Políticas de descentralização e atenção primária à saúde. In: Epidemiologia \& Saúde (M. Z. Rouquayrol \& N. Almeida Filho, org.), pp. 489-503, 5a Ed., Rio de Janeiro: MEDSI.

PORTO, S. M., 1995. Justiça social, eqüidade e necessidade em saúde. In: Economia da Saúde: Concei to e Contribuição para a Gestão da Saúde (S. F. Piola \& S. M. Viana, org.), pp. 123-140, Brasília: Instituto de Pesquisa Econômica Aplicada.

RAWLS, J., 1992. Justiça como eqüidade: U ma concepção política não metafísica. Lua Nova, 25:2559.

ROSA, C. M. M. (org.), 1995. População de Rua: Brasil e Canadá. São Paulo: Editora Hucitec.

SALES, T., 1994. Raízes da desigualdade social na cultura política brasileira. Revista Brasileira de Ciências Sociais, 25:26-37.

SANTOS, M., 1994. Por uma Economia Política da Cidade: O Caso de São Paulo. São Paulo: Editora Hucitec/Educ.

SÃO PAULO (Município), 1992. Lei Municipal n. 11.220, de 20 de maio de 1992. Institui a divisão geográfica da área do Município em Distritos, revoga a Lei n. 10.932, de 15 de janeiro de 1991, e dá outras providências. São Paulo: Diário Oficial do Município, 21 maio.

SÃO PAULO (Município), 2002. Desigualdade em São Paulo: O IDH. São Paulo: Secretaria de Desenvolvimento, Trabalho e Solidariedade, Prefeitura do Município de São Paulo.

SCHRAIBER, L. B. \& MENDES-GONÇALVES, R. B., 1996. Necessidades de saúde e atenção primária. In: Saúde do Adulto: Programas e Ações na Unidade Básica (L. B. Schraiber, M. I. B. Nemes \& R. B. Mendes-Gonçalves, org.), pp. 29-47, São Paulo: Hucitec.

SPOSATI, A. (org.), 2000. Mapa da Exclusão/Inclusão Social da Cidade de São Paulo 2000. São Paulo: Pontifícia Universidade Católica de São Paulo/ Instituto Pólis/Instituto Nacional de Pesquisas Espaciais.

SILVEIRA, C., 1999. O Significado da Prática Profissional e do Ensino em uma Unidade Básica de Saúde. Tese de Doutorado, São Paulo: Faculdade de Saúde Pública, Universidade de São Paulo.

VIEIRA, M. A. C.; BEZERRA, E. M. R. \& ROSA, C. M. M. (org.), 1992. População de Rua: Quem é, Como Vive, Como é Vista. São Paulo: Editora Hucitec.

VITA, A., 1992. A tarefa prática da filosofia política em John Rawls. Lua Nova, 25:5-24.

Recebido em 26 de novembro de 2002

Versão final reapresentada em 30 de maio de 2003

Aprovado em 18 de agosto de 2003 